\title{
Post-operative stifle range of motion in dogs with medial patellar luxation undergoing either trochlear wedge recession or trochlear block recession surgery
}

\section{Radka S. Garnoeva}

Research Article

Volume: 5, Issue: 1 April 2021

Pages: 27-31

\section{Article History}

Received: 26.01.2021

Accepted: 21.03.2021

Available online:

07.04.2021
Department of Veterinary Surgery, Faculty of Veterinary Medicine, Trakia University, 6000 Stara Zagora, Bulgaria. ORCID ID: 0000-0002-3373-3468

\begin{abstract}
The aim of this study was to evaluate post-operative range of motion of stifle joints in dogs affected with medial patellar luxation in order to compare two surgical techniques: trochlear wedge recession vs. trochlear block recession. The study was done with 67 joints from 54 small breed dogs (21 Mini-Pinschers, 16 Chihuahuas, 11 Pomeranians and 6 Yorkshire terriers). From these, 31 joints underwent wedge recession surgery and the other 36 : block recession surgery. In wedge recession surgery, trochlear groove deepening was done by removal of a $V$-shaped wedge, whereas in block recession, the wedge was rectangular. Block recession is suggested to provide a deeper and wider trochlea with preservation of the major part of the articular cartilage. The results suggested that both trochleoplasty techniques resulted in reduction of joint range of motion and improvement of limb alignment at the first post-operative month.
\end{abstract}

Keywords: medial patellar luxation, dogs, goniometry, block recession, wedge recession

DOI: https://doi.org/10.30704/http-www-jivs-net.868512

To cite this article: Garnoeva, R. S. (2021). Post-operative stifle range of motion in dogs with medial patellar luxation undergoing either trochlear wedge recession or trochlear block recession surgery. Journal of Istanbul Veterinary Sciences, 5(1), 27-31. Abbreviated Title: J. İstanbul vet. sci.

\section{Introduction}

Medial patellar luxation is a common hereditary orthopedic condition in small breeds of dogs (Wangdee et al., 2013). The evaluation of bone deformities by radiography is important for decision making about the operative technique (Tomlinson et al., 2007). The aim of the surgical correction is to provide stability of the patella and to restore the normal quadriceps muscle mechanism. Surgery should not be postponed due to the risk from aggravation of tissue damage and bone deformities (Wangdee et al., 2008; Wangdee \& Torwattanachai, 2010).
Results from comparative assessment of the superiority of wedge and block recession of the trochlear groove are contradictory (Linney et al., 2011; Fujii et al., 2013; Wangdee et al., 2013). The depth of the trochlea is essential for the stability of the patella (Talcott et al., 2000).

Older cases of MPL are most prone to development of secondary osteoarthritis with progressive joint cartilage erosion and bone lesions (Edge-Hughes \& Nicholson, 2007). Early signs of occurring degenerative joint disease are pain and reduced joint range of motion (ROM). 
The latter could be due to contracture of soft tissues caudal to the joint or to irreversible epiphyseal damage, especially in young animals. Such pathological alterations could affect postoperative stifle joint ROM and compromise surgery outcome (Olmstead, 1995).

The aim of this study was to compare postoperative range of motion of stifle joints in dogs with medial patellar luxation corrected by two surgical techniques: wedge recession and block recession of femoral trochlea.

\section{Materials and Methods}

Comparative studies were carried out for evaluation of two surgical techniques for treatment of canine MPL - trochlear wedge recession and trochlear block recession of femoral trochlea in 54 dogs (67 joints) with MPL grade II and III in four small breeds (21 MiniPinschers, 11 Pomeranians, 16 Chihuahuas and 6 Yorkshire Terriers). Forty-one dogs underwent surgery of one stifle only, while in 13 both stifles were operated. None of patients had data for preceding traumatic injury. The study included only dogs with grade II MPL (41 joints) and grade III MPL (26 joints). Out of them, 36 joints were submitted to block recession surgery, and 31: to wedge recession surgery. All interventions were done by the same surgeon.

Stifle joint ROM values were measured preoperatively and 1 month after the surgery with a transparent plastic goniometer. Prior to measurements, dogs were anaesthetized as followed: s.c. premedication with $0.02 \mathrm{mg} / \mathrm{kg}$ atropine sulfate (Atropinum sulfuricum, Sopharma, Sofia - Bulgaria) and induction of anaesthesia $15 \mathrm{~min}$ later with $7.5 \mathrm{mg} / \mathrm{kg}$ i.v. tiletamine hydrochloride and zolazepam hydrochloride (Zoletil $^{\circledR}$ 50, Virbac, France). For measurements, patients were in lateral recumbency with studied limb exposed. The centre of the goniometer was placed in the center of stifle joint rotation determined previously by flexion and extension of the joint. The stationary arm of the device was placed along the longitudinal axis of the femur determined by the line connecting trochanter major and the centre of lateral femoral epicondyle, while the lever was aligned on the line joining the lateral maleollus and proximal part of the tibia, caudally to the tibial crest (Figure 1). The angles of full

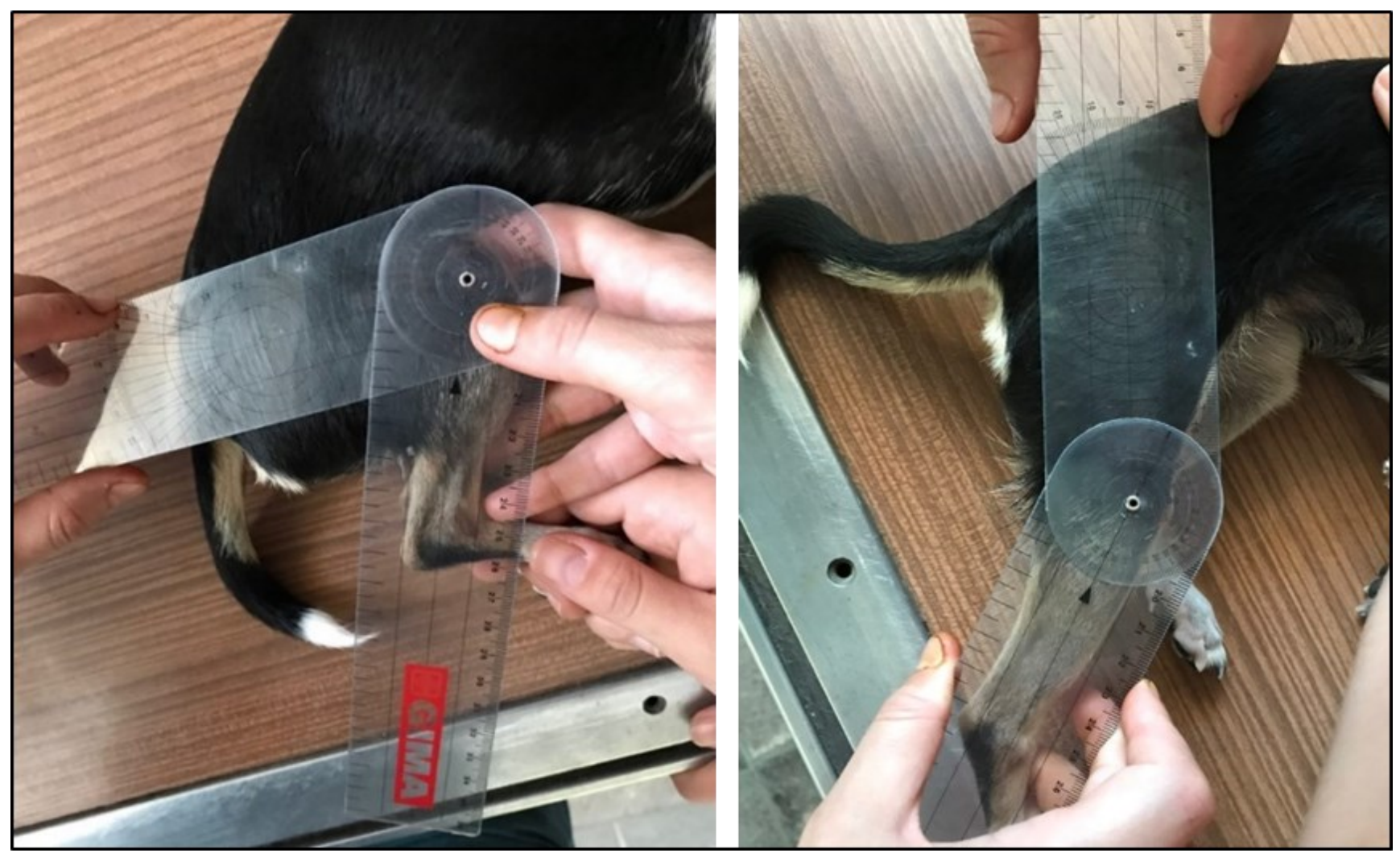

Figure 1. Measurement of full flexion (left) and full extension (right) angles 
flexion and full extension of the joint were measured in degrees.

The non-parametric Mann-Whitney test was used to determine the differences between healthy joints and joints affected by various MPL grades. Values are presented as median [range]. Differences were considered significant at $p<0.05$.

\section{Results}

Before the surgery, median ROM of affected knees was $97^{\circ}$, and one month after block recession surgery, it decreased to $95.5^{\circ}(p=0.09$; Figure 2). The same tendency was observed in joints that underwent trochlear wedge recession surgery (Figure 3 ) - higher preoperative ROM $\left(98^{\circ}\right)$, which decreased to $91^{\circ}$ at the first post-

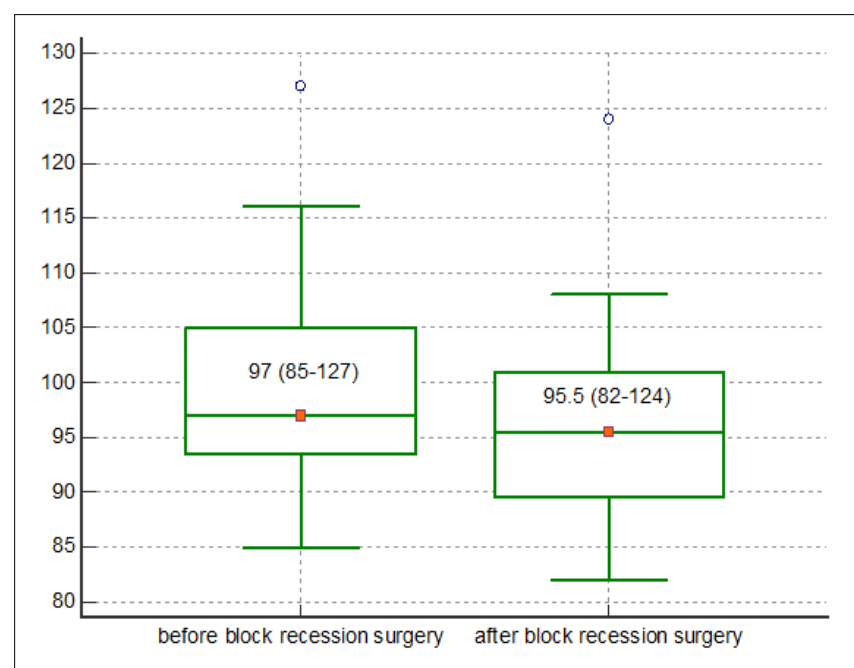

operative month $(p=0.0079)$.

Figure 2. Stifle joint range of motion (degrees) in 36 patients undergoing block recession surgery - prior to and one month after the intervention. Values are presented as median (minimum-maximum range).

\section{Discussion}

Goniometry in dogs could be performed either in standing position or in lateral recumbency. Due to pain and discomfort in affected joints during their flexion and extension (Thomas et al., 2006) this procedure was performed in our patients in lateral recumbency after general anaesthesia to eliminate pain.

Dog breeds differ considerably by their body structure, body shape and live weight. Therefore, flexion and extension angles of carpal, elbow, stifle and hip joints are quite different. Metric and goniometric studies are mainly performed in large canine breeds (hounds, Golden retriever,

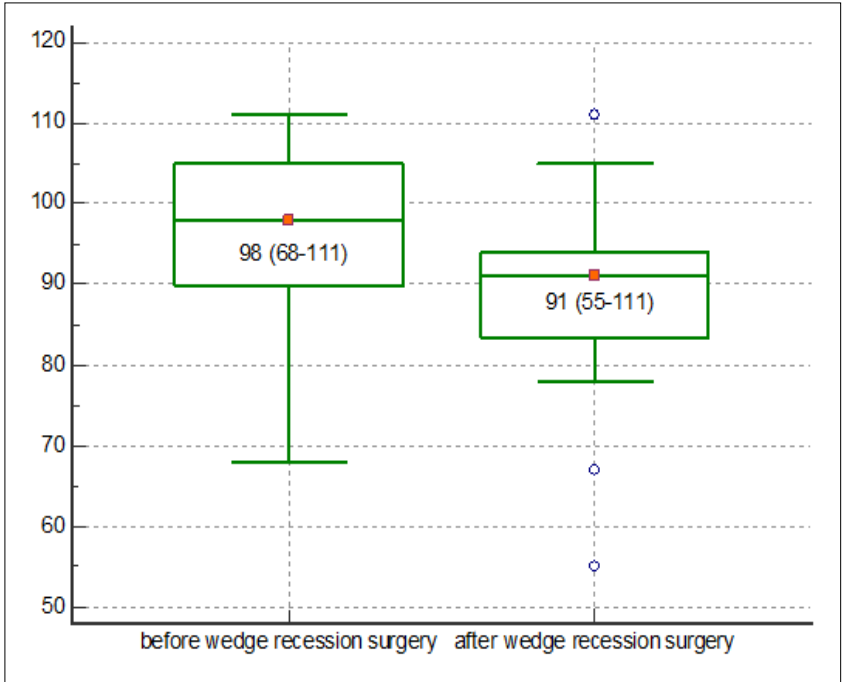

Figure 3. Stifle joint range of motion (degrees) in 31 patients undergoing wedge recession surgery - prior to and one month after the intervention. Values are presented as median (minimum-maximum range).

Labrador retriever, German shepherd, Kangal, Border Collie, Irish wolfhound etc.) for creation of reference values (Jaeger et al., 2002; Benson et al., 2004; Thomas et al., 2006; Hasbach, 2007; Ates et al., 2011; Hady et al. 2015). Other researcher teams (Ates et al., 2011) have compared between-sex goniometric parameters of thoracic and pelvic limb joints within breeds yet did not found out any statistically significant difference. Our study was done on small dog breeds which are more commonly affected by medial patellar luxation.

It should be noted that different dog breeds have extremely variable body shape, structure and body weight. This is reflected in angles of full flexion and full extension of joints whose reference values have to be breed-specific (Mann et al., 1988; Benson et al., 2004). In minidachshunds, goniometric exam is even almost impossible due to the shape of limbs and excessive muscle mass (Thomovsky et al., 2016). Luxation of patella alters the biomechanical properties of the stifle with resulting changes in full flexion and full extension angles (Thomas et al., 2006). Therefore clinical goniometry is an essential part of clinical examination of such patients (Petazzoni \& Jaeger, 2008). The available information about joint's range of motion after orthopedic surgery is scarce (Daems et al., 2009). In our study, ROM of stifle joint immediately prior to surgery was higher. This, in our opinion, could 
be attributed to higher full extension angle due to contracted $\mathrm{m}$. quadriceps femoris which at the same time, did not allow full flexion of the joint, e.g. higher flexion angle.

After both surgical interventions, stifle ROM decreased, but this change was statistically significant only after wedge recession surgery. At present, we could not provide a logical explanation of this fact. Radiography in mediolateral and craniocaudal views did not establish any changes that could be responsible because possible changes are in soft tissues and not in bones, hence are not visible on radiographs.

It was reported that following block recession surgery, recovery of limb function was faster and what is more, signs of degenerative joint disease were less severe (Johnson et al., 2001). In our survey, similar findings were also recorded perhaps due to preservation of the major part of joint cartilage after block recession surgery of trochlea.

\section{Conclusion}

In dogs with grade II and III medial patellar luxation, both applied trochleoplasty techniques resulted in decreased range of motion of operated joints, which was preoperatively increased by $\mathrm{m}$. quadriceps femoris contracture. By the end of the first post-operative month, dogs demonstrated fairly good use of the operated limb as the reduced joint range of motion improved limb's clinical state and alignment.

\section{References}

Ates, S, Hallaceli, C, Hallaceli, H, \& Kürtül I. (2011). Goniometric measurements of the angular values of the joints in the fore- and hind limbs of Kangal dogs. Israel Journal of Veterinary Medicine, 66, 166-170.

Benson, C, Lakey, S, Smith, M, \& Hummel-Berry, K (2004). A comparison of canine range of motion measurements between two breeds of disparate body types, Abstract. Journal of Orthopedic and Sports Physical Therapy, 34, 39.

Daems, R, Janssens, L. A, \& Beosier, Y. M. (2009).
Grossly apparent cartilage erosion of the patellar articular surface in dogs with congenital medial patellar luxation. Veterinary and Comparative Orthopaedics and Traumatology, 22, 222-224.

Edge-Hughes, L, \& Nicholson, H. (2007). Canine treatment and rehabilitation. In: McGowan, $\mathrm{C}$. M., Goff, L., Stubbs, N. (Eds.), Animal Physiotherapy: Assessment, Treatment and Rehabilitation of Animals. Blackwell, Singapore, pp. 207-237.

Fujii K, Watanabe T, Kobayashi T, Hayashi K. (2013). Medial ridge elevation wedge trochleoplasty for medial patellar luxation: A clinical study in 5 dogs. Veterinary Surgery, 42 (6), 721-726.

Hady L. L., Fosgate G. T., Weh J. M. (2015). Comparison of range of motion in Labrador Retrievers and Border Collies. Journal of Veterinary Medicine and Animal Health, 7, 122 $-127$.

Hesbach A. L. (2007). Techniques for objective outcome assessment. Clinical Techniques in Small Animal Practice, 22, 146-154.

Jaegger, G, Marcellin-Little, D. J, \& Levine, D. (2002). Reliability of goniometry in Labrador Retrievers. American Journal of Veterinary Research, 63, 979-986.

Johnson, A. L., Probst, C. W., DeCamp, C. E., Rosenstein, D. S., Hauptman, J. G., Weaver, B. T., \& Kern, T. L. (2001). Comparison of trochlear block resession and trochlear wedge recession for canine patellar luxation using a cadaver model. Veterinary Surgery, 30, 140150.

Linney, W. R., Hammer, D. L., \& Shott, S. (2011). Surgical treatment of medial patellar luxation without femoral trochlear groove deepening procedures in dogs: 91 cases (1998-2009). Journal of the American Veterinary Medical Association, 238(9), 1168-1172.

Mann, F. A., Wagner-Mann, C, \& Tangner, C. H. (1988). Manual goniometric measurement of the canine pelvic limb. Journal of the American Animal Hospital Association, 24, 189-194. 
Olmstead, M. L. (1995). Canine cemented total hip replacements: state of the art. Journal of small Animal Practice, 36, 395-399.

Petazzoni, M, \& Jaeger, G. (2008). Atlas of clinical goniometry and radiographic measurements of the canine pelvic limb, Merial SAS, pp. 22-23.

Talcott, K. W., Goring, R. L., \& de Haan, J. J. (2000). Rectangular recession trochleoplasty for treatment of patellar luxation in dogs and cats. Veterinary and Comparative Orthopaedics and Traumatology, 13, 39-43.

Thomas, T. M., Marcellin-Little, D. J., Roe, S. C., Lascelles, B. D. X., \& Brosey, B. P. (2006). Comparison of measurements obtained by use of an electrogoniometer and a universal plastic goniometer for the assessment of joint motion in dogs. American Journal of Veterinary Research, 67, 1974-1979.

Thomovsky, S. A., Chen, A. V., Kiszonas, A. M., \& Lutskas, L. A. (2016). Goniometry and limb girth in Miniature Dachshunds. Journal of Veterinary Medicine, 2016, 5846052.

Tomlinson, J., Fox, D., Cook, J. L., \& Keller, G. G. (2007). Measurement of femoral angles in four dog breeds. Veterinary Surgery, 36, 593-598.

Wangdee, C, \& Torwattanachai, P. (2010). Lateral patellar luxation in three Pomeranian dogs: $A$ case report. Thai Journal of Veterinary Medicine, 40(2), 227-231.

Wangdee, C., \& Kalpravidh, M. (2008). Tube realignment for patellar luxation repair in dogs. Thai Journal of Veterinary Medicine, 38, 39-44.

Wangdee, C, Theyse, L. F., \& Techakumphu, M. (2013). Evaluation of surgical treatment of medial patellar luxation in Pomeranian dogs. Veterinary and Comparative Orthopaedics and Traumatology, 26, 435-439. 